\title{
Student-centered tutoring as a model for patient-centeredness and empathy
}

\author{
This article was published in the following Dove Press journal: \\ Advances in Medical Education and Practice \\ 27 July 2016 \\ Number of times this article has been viewed
}

\section{Adaya Meirovich' \\ Rosalie Ber ${ }^{2}$ \\ Michael Moore 3 \\ Avi Rotschild ${ }^{4}$}

'Department of Management of Service Organizations, Hadassah Academic College, Jerusalem, ${ }^{2}$ Medical Education Unit, Ruth and Bruce Faculty of Medicine, ${ }^{3}$ Faculty of Education in Science \& Technology, ${ }^{4}$ Department of Neonatology, Carmel Medical Center, Ruth and Bruce Faculty of Medicine, Technion, Israeli Institute of Technology, Haifa, Israel
Correspondence: Adaya Meirovich Department of Management of Service Organizations, Hadassah Academic College, Arlozorove 8, Raanana 4360804, Israel

Tel +972 544422838

Email adayameirovich@gmail.com
Background: Curriculum planners and medical teachers attempt to enhance medical students' empathy and patient-centeredness. Despite educational efforts, there is stability in medical students' empathy and patient-centered medicine during the preclinical stage and a decline in both of them throughout the clinical years. Student-tutor relationship plays a key role in students' learning. This study tests the effect of learner-centered tutoring on students' empathy, patient-centeredness, and behavior.

Participants and methods: The cohort of 55 students was divided into groups of seven or eight. The experimental group's tutors underwent LC mentoring. Empathy was assessed with the Jefferson Scale of Physician Empathy for Students; PC attitude was assessed with the PatientProvider Orientation Scale (PPOS). Behavior was assessed by simulations of doctor-patient encounters with 32 students at the end of the third year. Each student participated in three such simulations, during which we analyzed ten aspects of physician-patient communication via Roter interaction analysis system (RIAS)-coded audiotapes.

Results: A significant group difference was found for three RIAS categories: building a relationship and patient-centeredness, where the mean percentage of the experimental group was significantly higher than that of the control group, and gathering data, where the mean percentage of the experimental group was significantly lower than that of the control group. A significant correlation was found in the experimental group between empathy and positive talk and between PPOS and three of the RIAS categories: gathering data, psychosocial talk, and patient-centeredness. A significant negative correlation was found in the experimental group between PPOS and two of the RIAS categories: negative talk and doctor-centeredness. Two significant negative correlations were found in the control group: between empathy and patient-centeredness and PPOS and negative talk.

Conclusion: The LC approach supports two of the RIAS categories, corresponding to clinical empathy and PC care and the link between certain behaviors and the PPOS.

Keywords: undergraduate, medical students, teaching methods, doctor-patient relationship, medical teacher, randomized controlled trial, health professional education

\section{Background}

Enhancing medical students' empathy and practicing patient-centered (PC) medicine is one of the goals of medical schools. ${ }^{1,2}$ Curriculum planners and medical teachers attempt to achieve this by a variety of programs and teaching methods: the use of simulated patients (SPs), case-based seminars, problem-based learning, integration between lectures, role-play, personal experiences, collaborative learning with peers, discussing ethical issues, beliefs, positions, power and culture, and having students observe excellent faculty physicians as role models. ${ }^{2-5}$ Despite these educational 
efforts, there is stability in medical students' empathy and PC during the preclinical stage ${ }^{4-9}$ and a decline in both of them throughout the clinical years. . $^{2,5,10-14}$

The relationship of students with their tutors plays a key role in students' learning. 5,15,16 "The learner-teacher relationship is as central to medical education as is the patient-doctor relationship to medical care." ${ }^{17}$ Kurtz et $\mathrm{al}^{7}$ and Kern et al ${ }^{8}$ state that the skills required to communicate effectively with the patients are the same as those required for teaching. This has led to a call for instructing tutors of medical students how to be more learner centered (LC)/student centered in their interactions with the students. The concept of LC (as well as PC) describes an interpersonal orientation in which people in positions of authority (such as educators or clinicians) encourage sharing concerns, expectations, preferences, and desires for information, while "teacher centered" (as well as "disease centered" or "physician centered"), and promotes dependency, passive reception of information, and more control by the person in the position of authority. ${ }^{18}$ The LC model emphasizes the importance of supportive classroom environments that foster positive, caring relationships. It refers to environments that pay careful attention to the knowledge, skills, attitudes, and beliefs that learners bring to the educational setting. The student-tutor relationship is a central part of the LC model and requires expertise in group facilitation skills. ${ }^{19}$ This approach is characterized by a collaborative relationship between the teacher and students, where all participants are actively engaged in the content and process of learning. ${ }^{20-22}$

Teaching PC through observing excellent faculty physicians as role models in the clinical years is considered to be the preferable mode in medical education. However, little evidence supports the effectiveness of small-group tutors as faculty role modeling. ${ }^{6}$ Although in small groups and problem-solving groups, teachers are requested to provide students with an active learning environment. They tend to teach in a teacher-centered manner, taking an active role in guiding the teaching, while students take a passive role in learning. ${ }^{21,23}$

The aim of this study was to test the effect of LC tutoring on the empathy, the PC attitudes, and the behavior of students.

\section{Participants and methods}

A cohort of 55 students was divided into eight groups with up to eight students per group. Written informed consent (in Hebrew) was obtained from all study participants. All the group tutors were coached in small-group teaching methods. In addition, throughout the three preclinical years, tutors of two randomly chosen groups received coaching in LC small-group instruction and tutoring methods. The experimental group of students was tutored by two tutors undergoing LC pedagogical mentoring. The control group was tutored by six tutors who were only coached in small-group teaching methods.

The study was conducted through the course "Exposure to the Medical Profession" (EMP) at the Technion Faculty of Medicine in Haifa, Israel, in a 6-year baccalaureate-MD program. During their first 3 years, all students attended a course in EMP, introducing students, from day 1, to the full range and complexity of health, illness, and various medical environments. A significant component of the course was that the facilitators' behaviors demonstrated the values and attitudes we wish our students to assimilate. The course ran weekly for 3 years, one semester/year, and was largely experiential. Throughout the 3 years, the students remained in the same small groups with the same tutors. The teaching strategy for the course involved interviews of patients, health personnel, and health professionals in diverse medical, clinical, and community environments. Following each session, debriefing, feedback, and free group discussions were held, in which the students were encouraged to reflect on their own behaviors and attitudes. They also discussed the advantages and disadvantages of different approaches and environments to professionalism and doctor-patient relationship.

\section{Participants}

The study participants were 55 medical students during their first three academic pre-clinical years - 2003, 2004, and 2005 . Their average age was 22.9 years (21-29 years), and $46 \%(n=25)$ of them were women. No significant differences were found in the background and demographic variables of the members of the eight groups participating in the study. The experimental group of students was those tutored by tutors who were randomly chosen to undergo LC pedagogical mentoring, and the control group consisted of students whose tutors were not coached in a LC pedagogical manner.

\section{Instruments}

Empathy was assessed with the Jefferson Scale of Physician Empathy for Students (JSPE-S). ${ }^{24}$ The JSPE-S is a 20 -item instrument using a 7-point Likert-type scale, from strongly disagree to strongly agree, with ten items that are reverse scored. The mean JSPE-S total score was calculated. The range was 20-140, with higher scores indicating higher empathy. The scale had been validated and shown to be a reliable tool. ${ }^{11,24-26}$

PC attitude was assessed with the Patient-Provider Orientation Scale (PPOS). ${ }^{27}$ The PPOS is an 18-item instrument, which uses a 6-point Likert-type scale from strongly disagree to strongly agree. The mean PPOS total score was calculated 
and ranged from 1 (doctor centered) to 6 (PC). The scale had been validated and shown to be a reliable tool. ${ }^{28,29}$

To assess the students' behavior, we conducted three simulations of doctor-patient encounters at the end of the third year. Thirty-two medical students participated in these three simulations with an SP. During these simulations, we analyzed physician-patient communication through a Hebrew translation of the Roter interaction analysis system (RIAS)-coded audiotape. ${ }^{30}$ RIAS provides a framework for understanding the communication dynamics between patients and physicians during a medical encounter. It has been utilized in a variety of countries, including Israel, ${ }^{31}$ and provides high levels of reliability and validity. ${ }^{30}$ We used RIAS to evaluate nine aspects of the medical encounter:

1. Open-ended questions - the percentage of the student's open questions.

2. Closed-ended questions - the percentage of the student's closed questions.

3. Gathering information - the percentage of questions (open and closed) of the SP and the student.

4. Building a relationship - the percentage of positive/negative/emotional/social statements of the SP and the student.

5. Positive-talk score was calculated by dividing the total number of interest/attentiveness, friendliness/warmth, responsiveness/engagement, and sympathy/empathy statements exhibited by the student by the total number of student statements.

6. Negative-talk score was calculated by dividing the total number of disagreement and criticism that the student exhibited by the total number of student statements.

7. Psychosocial talk included lifestyle and psychosocial talk by students and SP during the course of the encounter. Patient-centeredness and doctor-centeredness scores were calculated based on the method used by Ford et $\mathrm{al}^{32}$ and Mead and Bower. ${ }^{33}$

8. PC communication included the total amount of psychosocial talk by both students and SPs and all partnership-building, legitimating, emotional, and clarifying behaviors made by the students during the course of the encounter.

9. Doctor-centered communication included the total amount of biomedical question-asking, directive statements (instructive/guiding talks) made by the student, and information-giving by students and SPs during the course of the encounter.

We used SPSS (SPSS Inc., Chicago, IL, USA) for Windows 11.5 to examine the data, the Student's $t$-test of the mean of total JSPE-S and PPOS scores and RIAS for the group, and Spearman's correlation between third-year students' JSPE-S and RIAS and PPOS and RIAS.

\section{Results}

The study comprised a total of 55 students each year. Of these, 32 students were included in a simulation of medical encounters at the end of the third year $(58.2 \%$ of the basic cohort, $84.2 \%$ of the third-year cohort, $n=38$ ).

A significant group difference was found for three of the RIAS categories: "building a relationship" and "patientcenteredness", where the mean percentage of the experimental group was significantly higher than that of the control group, and "gathering data", where the mean percentage of the experimental group was significantly lower than that of the control group (Table 1).

A significant correlation was found in the experimental group between empathy and "positive talk" $(\rho=0.66, P<0.01)$ and between PPOS and three of the RIAS categories: "gathering data" ( $\rho=0.46, P<0.05)$, "psychosocial talk" $(\rho=0.44, P<0.05)$, and "patient-centeredness" $(\rho=0.43, P<0.05)$. A significant negative correlation was found in the experimental group between PPOS and two of the RIAS categories: "negative talk" ( $\rho=-0.47$, $P<0.05)$ and "doctor-centeredness" $(\rho=-0.43, P<0.05)$. Two significant negative correlations were found in the control group: between empathy and "patient-centeredness" $(\rho=-0.51, P<0.05)$ and PPOS and "negative talk" ( $\rho=-0.44, P<0.05$; Table 2$)$.

No significant group differences in empathy and patientprovider orientation were observed ( $t$-test, $P>0.05$; empathy

Table I Mean scores of behavior in the simulated medical interview by the experimental and control groups

\begin{tabular}{|c|c|c|c|c|}
\hline \multirow[t]{2}{*}{ RIAS categories } & \multicolumn{2}{|c|}{$\begin{array}{l}\text { Experimental group }{ }^{a} \\
(n=16)\end{array}$} & \multicolumn{2}{|c|}{$\begin{array}{l}\text { Control group } \\
(n=16)\end{array}$} \\
\hline & Mean \% & SD & Mean \% & SD \\
\hline $\begin{array}{l}\text { Open-ended } \\
\text { questions }\end{array}$ & 64.8 & 7.1 & 59.9 & 10.9 \\
\hline $\begin{array}{l}\text { Close-ended } \\
\text { questions }\end{array}$ & 35.2 & 7.1 & 40.1 & 10.9 \\
\hline Gathering data* & 15.1 & 4.1 & 17.4 & 2.8 \\
\hline $\begin{array}{l}\text { Building a } \\
\text { relationship* }\end{array}$ & 22.0 & 4.4 & 19.5 & 3.9 \\
\hline Positive talk & 8.5 & 4.0 & 9.6 & 4.6 \\
\hline Negative talk & 0.44 & 0.78 & 0.27 & 0.47 \\
\hline Psychosocial talk & 23.5 & 10.2 & 27.2 & 6.8 \\
\hline $\begin{array}{l}\text { Patient- } \\
\text { centeredness* }\end{array}$ & 44.6 & 8.3 & 40.6 & 6.7 \\
\hline $\begin{array}{l}\text { Doctor- } \\
\text { centeredness }\end{array}$ & 50.4 & 8.6 & 52.3 & 6.7 \\
\hline
\end{tabular}

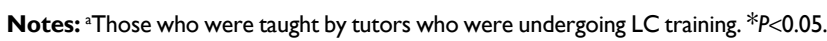
Abbreviations: LC, learner-centered; RIAS, Roter interaction analysis system; SD, standard deviation. 
Table 2 Correlations between empathy and patient-provider orientation and behavior in the simulated medical interview by the experimental and control groups

\begin{tabular}{|c|c|c|c|c|}
\hline \multirow[t]{2}{*}{$\begin{array}{l}\text { RIAS } \\
\text { categories }\end{array}$} & \multicolumn{2}{|c|}{$\begin{array}{l}\text { Experimental group } \\
(n=16)\end{array}$} & \multicolumn{2}{|c|}{$\begin{array}{l}\text { Control group } \\
(n=16)\end{array}$} \\
\hline & Empathy & $\begin{array}{l}\text { Patient- } \\
\text { provider } \\
\text { orientation }\end{array}$ & Empathy & $\begin{array}{l}\text { Patient- } \\
\text { provider } \\
\text { orientation }\end{array}$ \\
\hline $\begin{array}{l}\text { Open-ended } \\
\text { questions }\end{array}$ & -0.17 & 0.14 & -0.18 & -0.29 \\
\hline $\begin{array}{l}\text { Close-ended } \\
\text { questions }\end{array}$ & 0.17 & -0.14 & 0.18 & 0.29 \\
\hline Gathering data & -0.08 & $0.46 *$ & 0.19 & -0.11 \\
\hline $\begin{array}{l}\text { Building a } \\
\text { relationship }\end{array}$ & 0.10 & -0.24 & -0.34 & 0.22 \\
\hline Positive talk & $0.66 * *$ & 0.34 & -0.07 & 0.20 \\
\hline Negative talk & -0.33 & $-0.47^{*}$ & 0.36 & $-0.44^{*}$ \\
\hline $\begin{array}{l}\text { Psychosocial } \\
\text { talk }\end{array}$ & 0.06 & $0.44^{*}$ & -0.33 & 0.32 \\
\hline $\begin{array}{l}\text { Patient- } \\
\text { centeredness }\end{array}$ & -0.09 & $0.43 *$ & $-0.5 \mathrm{I}$ & 0.37 \\
\hline $\begin{array}{l}\text { Doctor- } \\
\text { centeredness }\end{array}$ & 0.09 & $-0.43^{*}$ & 0.16 & -0.11 \\
\hline
\end{tabular}

Notes: ${ }^{\text {TT }}$ Those who were taught by tutors who were undergoing LC training. ${ }^{*} P<0.05$. $* * P<0.0$ I.

Abbreviations: LC, learner-centered; RIAS, Roter interaction analysis system.

- experimental group: mean 104.1, SD 10.6 and control group: mean 105.4, SD 10.2 and PPOS - experimental group: mean 4.21, SD 0.37 and control group: mean 4.26, SD 0.43).

\section{Discussion}

Our basic hypotheses were that student-teacher relationships serve as a model for patient-physician relationships and that a parallel process exists between tutoring and medicine. We found three important differences at the level of students' behavior between the experimental and control groups. The students of the experimental group were more PC and received higher scores at "building relationship", but were lower at the "gathering data" category in comparison with the students of the control group. This can be due to the shifting of the experimental group's tutoring style from "expert" to "coach", while the control group's tutoring style remained expert.

Our findings show two links between empathy and behavior: a positive link of "positive talk" in the experimental group and a negative link of "patient-centeredness" in the control group. Five links were found between PPOS and behavior in the experimental group: positive links of "gathering data", "psychosocial talk", and "patient-centeredness" and negative links of "negative talk" and "doctor-centeredness". Only one of these links, "negative talk", was found in the control group.
The connections found in the study between empathy and other behaviors, as well as between PPOS and behaviors, are in accord with the previous studies. ${ }^{5,11}$

The "positive talk" category of RIAS refers to students' statements of interest/attentiveness, friendliness/warmth, responsiveness/engagement, and sympathy/empathy during the simulation. This aspect of the medical encounter refers to the ability to combine an understanding of the patient's inner experiences and perspectives with a capability to communicate this understanding to the patient, which is defined as cognitive empathy. ${ }^{11,12,33}$ The LC approach expands the students' components, which are similar to three of the six components of the PC care model of Stewart et $\mathrm{al}^{34}$ : 1) "exploring both the disease and the illness experience"; 2) "understanding the whole person"; 3) "enhancing the patient-doctor relationship".

It is possible that the lack of connection between empathy and behavioral categories in both groups is due to the complexity of empathy. Neumann et a ${ }^{35}$ suggest a synthesizing theory of empathy based on a multidisciplinary empathy theory: empathy as an affective event, empathy as a cognitive event, empathy as a behavior, empathy as a requirement for social support, empathy as a function of sex differences, and neurophysiologic indicators of empathy. Analyzing these connections in light of the theory of Neumann et $\mathrm{al}^{35}$ can reveal variations in the connections of the different aspects of empathy over group. In contrast, our results could be due to failure of the EMP course to achieve its goals. It could be due to the lack of routine reflection methods and lack of continuity in relationship between the tutors and the students since the course is conducted only one semester per year. (Incidentally, this has been modified and the EMP course now runs for two semesters per year and includes routine reflection.)

The LC educational approach had an effect on the student's behavior rather than on their attitudes and empathy. Maybe role modeling alone is not sufficient to create a deeper effect. The parallel processing of tutoring and medicine is very complex and includes many variables that were not investigated in this study, such as processes of association between attitudes and behaviors, processes of transfer of skills, the characteristics of the tutor's behavior as an agent of change, the students' perceptions of the tutor as a role model, the perception of students and tutors about parallel processing, and whether there are differences in such perceptions between students studying in the framework of different pedagogical approaches.

Tutoring style alone is not the sole component, and may even not be the central one, influencing empathy, PC, and 
behavior of the students. Other possible associated components are the organizational culture of the medical school, stressing efficiency and time constraints, a biomedical-oriented curriculum, the medical school's "hidden curriculum", exposure to other patient/physician relationships, distress experienced during the academic years, ${ }^{10}$ and the explicit and implicit messages that the students receive during their studies in general and in the EMP course in particular, where the students are exposed to a number of other patient/physician relationships besides that demonstrated by their tutors. This aspect is expressed, among others, in the amount of exposure the students have to medical interviews conducted by the group tutor with various patients and under various conditions, the extent to which students have opportunities to reflect and receive feedback regarding their learning and interviews with patients, and the development of a mentor-student relationship between tutors and students.

The LC approach to teaching empathy and PC requires a shift in curricular focus and faculty development by: 1) explicitly stressing the parallel process of tutoring and medical interviewing; 2) explicitly developing role modeling as a central element in the tutoring process; 3) developing a culture of good interpersonal relationships in the educational environment of the faculty and the course; and 4) developing tutor training and student support programs.

These recommendations are in accordance with the findings of the studies about the two key components of successful PC education: providing support relationship through studentcentered training and integrating reflection into training. 5,14

Our findings should be interpreted with caution due to the small number of students from each group. Generalization of the study is limited because the data were collected from a single medical school, where the curriculum includes the EMP course taught during the three preclinical years. Another limitation of the study is that the number of students who responded to the questionnaire declined each year. The small number of students in the simulations in each group may also have affected the significance of findings.

\section{Conclusion}

This study tried to meet the challenge of teaching empathy and PC medical practice through a LC tutoring/teaching process. It is based on the belief that teacher educators have an obligation to "practice what they preach". The main innovation of our study is the attempt to influence students' empathy and PC by faculty development. All the tutors chosen to instruct in the EMP course were recognized as good role models; two of them were "enriched" with LC tutoring. The study indicates that the LC approach supports two of the RIAS categories and the links between some behaviors, including patient-centeredness and the PPOS. These categories correspond to the concept of "clinical empathy" 36 and "PC care". 5,34 The first refers to "the skill of recognizing a patient's emotional status and responding, on the spot, to the unique needs of the patient to promote better clinical outcomes". ${ }^{36}$ The second refers to respectful care that explores patients' problems within a broad framework (physical, psychological, and social); responsiveness to patients' preferences, needs, and values; and sharing power and responsibility. ${ }^{33}$

The LC approach to teaching patient-centeredness relies on students' reflection abilities and their relationship with their mentors. It seems important that facilitators be enriched in the LC teaching approach, a concept that acknowledges the student-teacher relationship. In order to develop empathy and patient-centeredness in medical students, we recommend developing role modeling as a central element, together with a culture of good interpersonal relationships in the faculty.

Further research is needed to explore which behaviors are associated with empathy and patient-centeredness. We propose adding layers of communication, such as body language and the patient's perception of the students' empathy and PC.

Because the behavior measurements were performed at one time point only, we did not follow behavioral changes over time. Further longitudinal research is needed to follow cohorts of students throughout their clinical medical studies, as well as during their internship and residency years, regarding their empathy and behavior in medical encounters with SP and real patients.

\section{Disclosure}

The authors report no conflicts of interest in this work.

\section{References}

1. Roter DL, Hall JA. Physician gender and patient-centered communication: a critical review of empirical research. Annu Rev Public Health. 2004; 25:497-519.

2. Kaufman DM, Laidlaw TA, Langille D, Sargeant J, MacLeod H. Differences in medical students' attitudes and self-efficacy regarding patient-doctor communication. Acad Med. 2001;76(2):188.

3. Stepien KA, Baernstein A. Educating for empathy. J Gen Intern Med. 2006;21(5):524-530.

4. Batt-Rawden SA, Chisolm MS, Anton B, Flickinger TE. Teaching empathy to medical students: an updated, systematic review. Acad Med. 2013;88(8):1171-1177.

5. Lévesque M, Hovey R, Bedos C. Advancing patient-centered care through transformative educational leadership: a critical review of health care professional preparation for patient-centered care. J Healthc Leadersh. 2013;5:35-46.

6. Branch WT, Kern D, Haidet P, et al. Teaching the human dimensions of care in clinical settings. JAMA. 2001;286(9):1067-1074.

7. Kurtz S, Silverman J, Draper J. Teaching and Learning Communication Skills in Medicine. Oxford: Radcliffe Press; 1998.

8. Kern DE, Branch WT, Jackson JL, et al. Teaching the psychosocial aspect of care in the clinical setting: practical recommendation. Acad Med. $2005 ; 80: 8-20$. 
9. Woloschuk W, Harasym PH, Temple W. Attitude change during medical school: a cohort study. Med Educ. 2004;38(5):522-534.

10. Neumann M, Edelhäuser F, Tauschel D, et al. Empathy decline and its reasons: a systematic review of studies with medical students and residents. Acad Med. 2011;86(8):996-1009.

11. Hojat M, Mangione S, Nasca TJ, et al. An empirical study of decline in empathy in medical school. Med Educ. 2004;38(9):934-941.

12. Hojat M, Vergare MJ, Maxwell K, et al. The devil is in the third year: a longitudinal study of erosion of empathy in medical school. Acad Med. 2009;84(9):1182-1191.

13. Tsimtsiou Z, Kerasidou O, Efstathiou N, Papaharitou S, Hatzimouratidis K, Hatzichristou D. Medical students' attitudes toward patient-centered care: a longitudinal survey. Med Educ. 2007;41:146-153.

14. Bombeke K, Symons L, Debaene L, De Winter B, Schol S, Van Royen P. Help, I'm losing patient-centeredness! Experiences of medical students and their teachers. Med Educ. 2010;44(7):662-673.

15. Howe A. Patient-centered medicine through student-centered teaching: a student perspective on the key impacts of community-based learning in undergraduate medical education. Med Educ. 2001;35(7): 666-672.

16. Hassan T, Bani I, Ageely H, Fauzi M. An ideal medical teacher. Educ Med J. 2011;3(1):e54-e59.

17. Kanter SL, Groce V, Littleton EB. The learner-teacher relationship. Med Sci Educ. 2012;22(4):264-266.

18. Williams GC, Deci EL. The importance of supporting autonomy in medical education. Ann Intern Med. 1998;129:303-308.

19. Leung KK, Lue BH, Lee MB. Development of a teaching style inventory for tutor evaluation in problem-based learning. Med Educ. 2003;37(5): 410-416.

20. Candela L, Dalley K, Benzel-Lindley J. A case for learning-centered curricula. J Nurs Educ. 2006;45(2):59-66.

21. Schaefer KM, Zygmont D. Analyzing the teaching style of nursing faculty. Does it promote a student-centered or teacher-centered learning environment? Nurs Educ Perspect. 2003;24(5):238-245.

22. Conti GJ. The relationship between teaching style and adult student learning. Adult Educ Q. 1985;35(4):220-228.

23. Davis WK, Oh MS, Anderson RM, Gruppen L, Narin R. Influence of a highly focused case on the effect of small-group facilitators' content expertise on students' learning and satisfaction. Acad Med. 1994;69(8): 663-669.
24. Hojat M, Manigione S, Nasca TJ, et al. The Jefferson Scale of Physician Empathy: development and preliminary psychometric data. Educ Psychol Meas. 2001;61(2):349-365.

25. Hojat M, Gonnella JS. Eleven years of data on the Jefferson Scale of Empathy-Medical Student Version (JSE-S): proxy norm data and tentative cutoff scores. Med Princ Pract. 2015;24(4):344-350.

26. Hojat M, Gonnella JS, Mangione S, Nasca TJ, Magee M. Physician empathy in medical education and practice: experience with the Jefferson Scale of Physician Empathy. Semin Integr Med. 2003;1(1): $25-41$.

27. Krupat E, Putnam S, Yeager C. The fit between doctors and patients: can it be measured. J Gen Intern Med. 1996;11(suppl):134.

28. Krupat E, Rosenkranz SL, Yeager CM, Barnard K, Putnam SM, Inui TS. The practice orientations of physicians and patients: the effect of doctor-patient congruence on satisfaction. Patient Educ Couns. 2000; 39:49-59.

29. Krupat E, Yeager CM, Putnam SM. Patient role orientations, doctorpatient fit, and visit satisfaction. Psychol Health. 2000;15:707-719.

30. Roter D, Larson S. The Roter interaction analysis system (RIAS): utility and flexibility for analysis of medical interactions. Patient Educ Couns. 2002;46:243-251.

31. Margalit RS, Roter D, Dunevant MA, Larson S, Reis S. Electronic medical record use and physician-patient communication: an observational study of Israeli primary care encounters. Patient Educ Couns. 2006; 61(1):134-141.

32. Ford S, Fallowfield L, Lewis S. Doctor-patient interactions in oncology. Soc Sci Med. 1996;42(11):1511-1519.

33. Mead N, Bower P. Measuring patient-centeredness: a comparison of three observation-based instruments. Patient Educ Couns. 2000;39: 71-80.

34. Stewart M, Weston WW, McWhinney IR, McWilliam CL, Freeman TR. Patient-Centered Medicine: Transforming the Clinical Method.Abingdon, UK: Radcliffe Medical Press; 2003.

35. Neumann M, Bensing J, Mercer S, Ernstmann N, Ommen O, Pfaff H. Analyzing the "nature" and "specific effectiveness" of clinical empathy: a theoretical overview and contribution towards a theory-based research agenda. Patient Educ Couns. 2009;74(3):339-346.

36. Dow AW, Leong D, Anderson A, Wenzel RP, VCU Theater-Medicine Team. Using theater to teach clinical empathy: a pilot study. $J$ Gen Intern Med. 2007;22(8):1114-1118.
Advances in Medical Education and Practice

\section{Publish your work in this journal}

Advances in Medical Education and Practice is an international, peerreviewed, open access journal that aims to present and publish research on Medical Education covering medical, dental, nursing and allied health care professional education. The journal covers undergraduate education, postgraduate training and continuing medical education

\section{Dovepress}

including emerging trends and innovative models linking education, research, and health care services. The manuscript management system is completely online and includes a very quick and fair peer-review system. Visit http://www.dovepress.com/testimonials.php to read real quotes from published authors. 